\title{
Developing Model for Critical Slip Surface in Slope Stability Analysis based on Geometry and Soil parameters
}

\author{
Worku Firomsa $^{1 *}$, Damtew Tsige \\ ${ }^{1}$ Department of Civil engineering, Jimma University, Ethiopia
}

DOI: $10.36348 /$ sjce.2021.v05i03.001 | Received: 22.02.2021 | Accepted: 03.03.2021 | Published: 29.04 .2021

*Corresponding author: Worku Firomsa

\section{Abstract}

The critical failure surface for a given slope can be determined by comparing factor of safety of several trial slip surfaces. To find the minimum factor of safety, it is important to get critical failure surface for the given slope. Different searching and optimization methods that had the difficulty in using them for hand calculations have been used in the past. In this study, effect of soil strength parameters; cohesion (c), internal friction angle $(\phi)$, and unit weight $(\gamma)$ on the failure surface and factor of safety of the slope were studied. GEO5 software program were used to calculate the length of failure and determine the critical failure surface. An equation was introduced in to locate the critical failure surface by using soils strength and slope geometry parameters. The results of the study showed that the factor of safety of the slope changes with varying cohesion $\mathrm{c}$, internal friction angle $\phi$, and the unit weight $\gamma$ of the soil. Moreover, the slip surface is affected by the dimensionless function $(\lambda)$, which is related to the cohesion, internal friction angle and unit weight. Model was introduced in to locate the critical failure surface by using soils strength and slope geometry.

Keywords: Critical Failure Surface, Factor of Safety, GEO5, Limit Equilibrium Method, Soil Slope Stability.

Copyright (C) 2021 The Author(s): This is an open-access article distributed under the terms of the Creative Commons Attribution 4.0 International License (CC BY-NC 4.0) which permits unrestricted use, distribution, and reproduction in any medium for non-commercial use provided the original author and source are credited.

\section{INTRODUCTION}

Calculating the safety factor of slopes is important in a number of engineering applications. These include natural slopes and manmade slopes such as embankments, earth dams, hydraulically constructed dams, etc. In recent years finite element methods have been developed for slope stability analyses [1, 2], but limiting equilibrium methods are still widely used. One of the major advantages of limiting equilibrium methods is that a single numerical value is calculated to give an indication of the "safety" against failure of the slope under consideration. This value is often called the "factor of safety". The factor of safety simplifies the interpretation of the analysis results as only one number has to be evaluated. Numerous definitions of the factor of safety have been proposed to date [3].

Limiting equilibrium methods require the critical failure surface to be determined as part of the analysis. The critical failure surface is defined as the surface for which the factor of safety is a minimum and the majority of analysis techniques require a priori assumptions with regard to the geometry of the failure surface. Search techniques suitable to find the critical failure surface for such regular shaped failure surfaces include random methods [4, 5] and grid contour methods [6, 7]. Other examples include a method developed by Carter [8] which searches for non-circular surfaces generated by a Fibonacci series. For nonhomogeneous slopes with a weak layer, Siegel [9] developed a random method where movement of failure surface nodes are restricted within specified zones. Some methods have been developed which do not require a priori assumptions with regard to the shape of the failure surface. These methods vary with respect to the restrictions on the failure surface geometry and boundary conditions. Revilla and Castillo [10] used calculus of variations to find critical non-regular failure surfaces for slope stability problems.

Nguyen [11] developed a method where the factor of safety is formulated as a multivariate function $\mathrm{F}(\mathrm{x})$ with the independent variables $\mathrm{x}$ describing the geometry of the failure surface, which can be circular or non-circular. Celestine and Duncan [12] used the same approach for non-circular failure surfaces, but used the alternating-variable optimization technique. $\mathrm{Li}$ and White [13] proposed a more efficient one-dimensional 
optimization technique to replace the quadratic interpolation method which Celestine and Duncan [12] used in the alternating-variable technique. Baker [14] defined the failure surface by a number of nodal points connected by straight lines. Recently, workers have addressed the problem by using a genetic algorithm that determines the critical slip surface for a multiple wedge stability analysis [15].

\section{MATERIALS AND METHODS}

In this study, different number of soil types with different strength parameters has been used to be analyzed. In order to generate models with enough accuracy in finding the relation between the soil strength parameters and the failure surface different soil types with small changes in soil strength parameters were selected and analyzed. The effect of water table is neglected by assuming the soil is dry.

The effect of unit weight $(\gamma)$, cohesion $(c)$, and the internal friction angle $\phi$ of the soil is studied on the factor of safety and the location of the failure surface will be determined by using the same soil parameters. The sufficient numbers of slopes will be modeled with varying soil shear strength parameters, unit weights, and slope geometry in order to create a database of failure surfaces regarding these slope parameters. Multi-variable regression was carried out in the database created in the second part of the study, to find a numerical formula to locate the failure surface. The study was performed by using the GEO5 software; Slope-Stability v16.The result of analyzing each model was entered and stored into latest version of Microsoft Excel a spread sheet program. After this step, using this software, different figures will be generated. Using Statistical Package for the Social Sciences (SPSS), regression was carried out in order to find a relation between input and output data.

\section{RESULTS AND DISCUSSIONS Effect of Soil Strength and Geometry Parameters on Factor of Safety}

Three series of modelling have been performed. In each set of models, one of the parameters varied while the other two remained constant. These models have been studied to see if there is any correlation between soil strength parameters and the position of the failure surfaces.

\section{Effect of Unit weight, $\gamma$ on the factor of safety, FS}

To study the effect of unit weight on the factor of safety, the unit weight values varying from 15-30 $\mathrm{kN} / \mathrm{m} 3$ were chosen while the cohesion and the internal friction angle were taken as $30 \mathrm{kPa}$ and 30 degrees, respectively.

\section{Effect of Cohesion, c on the Factor of Safety, FS}

With the aim of studying the influence of cohesion, $\mathrm{c}$ on the factor of safety of the soil, different values of c changing from 30 to $15 \mathrm{kPa}$ were chosen, while the unit weight of the soil and the friction angle were kept constant at $30 \mathrm{kN} / \mathrm{m} 3$ and 30 degrees, respectively.

Table-1: Effect of Unit weight, $\boldsymbol{\gamma}$ on the factor of safety, FS
\begin{tabular}{|l|l|l|}
\hline Model No & Unit Weight (kN/m3) & Factor of Safety \\
\hline 1 & 15 & 2.29 \\
\hline 2 & 20 & 1.81 \\
\hline 3 & 25 & 1.55 \\
\hline 4 & 30 & 1.31 \\
\hline
\end{tabular}

Table-2: The factor of safety for varying cohesion values

\begin{tabular}{|l|l|l|}
\hline Model No & Cohesion (kPa) & Factor of Safety \\
\hline 1 & 30 & 1.31 \\
\hline 2 & 25 & 1.18 \\
\hline 3 & 30 & 1.01 \\
\hline 4 & 15 & 0.83 \\
\hline
\end{tabular}

Table- 1 above shows that as the unit weight of the soil increased, the factor of safety values was decreased because of the unit weight which is the main cause of the driving forces. Table- 2 above shows that factor of safety decreases by reducing the value of cohesion. Since cohesion is one of the resisting forces, the obtained result is in harmony with the theory.

\section{Effect of Friction Angle ( $\varphi$ ) on the Factor of Safety,} FS

To observe the influence of friction angle, cohesion is fixed to $30 \mathrm{kPa}$ and the unit weight remains at $30 \mathrm{kN} / \mathrm{m} 3$ while friction angle decreases from 30 to 15 degrees.

\section{Effect of Slope Geometry on the Factor of Safety}

With the intention of observing the effect of slope shape on the factor of safety, four different slope shapes have been analysed with constant soil strength parameters: $\mathrm{c}=15 \mathrm{kPa}, \gamma=15 \mathrm{kN} / \mathrm{m} 3$, and $\varphi=15^{\circ}$. The result shows that the Factor of safety $1.49,1.40,1.20$ and 1.14 for Shape No 1, 2, 3 and 4 respectively. 
Table-3: The factor of safety for varying friction angle values

\begin{tabular}{|r|r|r|}
\hline Model No & Friction Angle $^{\left({ }^{\circ}\right)}$ & Factor of Safety \\
\hline 1 & 30 & 1.31 \\
\hline 2 & 25 & 1.18 \\
\hline 3 & 20 & 1.01 \\
\hline 4 & 15 & 0.83 \\
\hline
\end{tabular}
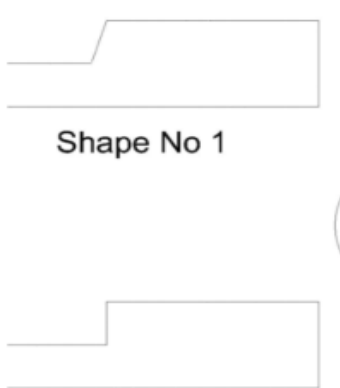

Shape No 3

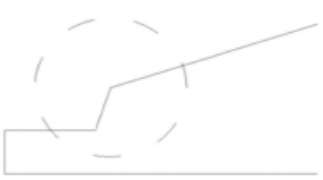

Shape No 2

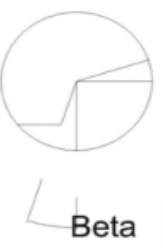

Beta

\section{Shape No 4}

Fig-1: Effect of Slope Geometry on FS, Model

Table-3 shows that factor of safety decreases by dropping the value of internal friction angle; again this is normal since friction is the other resisting force.

Considering cases Number 1 and 2 together, and 3 and 4 together (Figure-1), it is observed that increasing the angle of surface soil (Alpha-see Fig-1) will cause the slope to be less stable; this might be because of the fact that this amount of added soil to the top part will act like an overhead load increasing the driving force and causing the factor of safety to decrease.

On the other hand, considering cases Number 1 and 3 together, and 2 and 4 together, it is observed that decreasing the slope angle (Beta), will cause the slope to be more stable; this might be because of the fact that by decreasing this angle, the length of arc is increasing and this will lead to a more resisting force which will make the factor of safety increase.

\section{Effect of Soil Strength and Geometry Parameters on Slip Surface}

Based on section 3.1 above, it is predictable that there should be a correlation of soil strength parameters and slope geometry with the failure surface. In order to analyse this condition, numerous models have been generated using GEO5 software. The function of cohesion $\mathrm{c}$, internal friction angle $\varphi$, unit weight $\gamma$ and height of the slope $h$ as [16]:

$$
\lambda=\frac{c}{(\gamma h \tan (\phi))} .
$$

The output data is the factor of safety, coordinates of centre of the slip circle and the radius of the circular failure surface. To find the length of failure slip and locating the entry point in the slope area, the circles were drawn by using AutoCAD software.

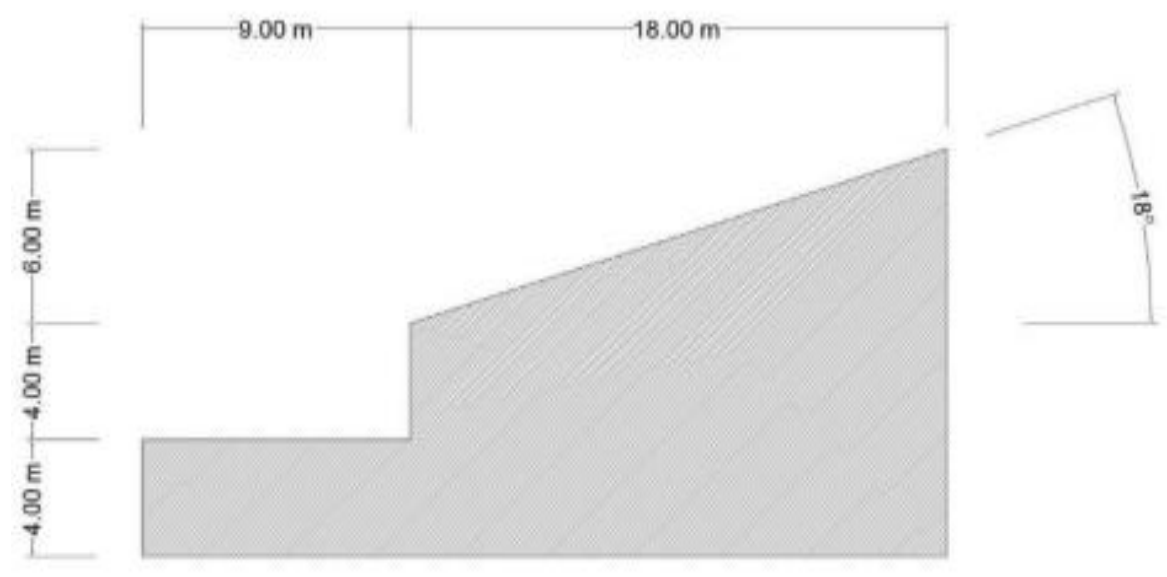

Fig-2: Slope model geometry 
Worku Firomsa \& Damtew Tsige, Saudi J Civ Eng, Apr, 2021; 5(3): 60-73

Figure-2 shows the general shape of the geometry of the slope that was used in the first 72 of the models (before studying the slope geometry). The generated models have been analyzed by considering different soil unit weight and shear strength parameters. The details of these parameters are given and discussed in the upcoming sections.

\section{Effect of Cohesion, $c$ on the Slip Surface}

In this part, the soil's unit weight and friction angle remained constant at $15 \mathrm{kN} / \mathrm{m} 3$ and $15^{\circ}$ respectively, and the cohesion varied from 15 to $32 \mathrm{kPa}$.

Table-4: Models, Cohesion (C) values selected for the Slip Surface Analyses

\begin{tabular}{|c|c|c|c|c|c|}
\hline $\begin{array}{l}\text { Model } \\
\text { No }\end{array}$ & $\begin{array}{l}\text { Cohesion } \\
(\mathbf{k P a})\end{array}$ & $\boldsymbol{\lambda}$ & $\begin{array}{l}\text { Entry Point } \\
\text { Distance, } \mathbf{l}(\mathbf{m})\end{array}$ & $\begin{array}{l}\text { Length of } \\
\text { Failure Arc (m) }\end{array}$ & $\begin{array}{l}\text { Factor of } \\
\text { Safety }\end{array}$ \\
\hline 1 & 15 & 0.75 & 2.92 & 5.90 & 1.08 \\
\hline 2 & 16 & 0.80 & 2.97 & 5.93 & 1.14 \\
\hline 3 & 17 & 0.85 & 3.05 & 5.99 & 1.21 \\
\hline 4 & 18 & 0.90 & 3.13 & 6.10 & 1.26 \\
\hline 5 & 19 & 0.96 & 3.27 & 6.03 & 1.33 \\
\hline 6 & 20 & 1.01 & 3.23 & 6.16 & 1.39 \\
\hline 7 & 21 & 1.06 & 3.29 & 6.17 & 1.45 \\
\hline 8 & 22 & 1.11 & 3.24 & 6.17 & 1.50 \\
\hline 9 & 23 & 1.16 & 3.26 & 6.18 & 1.56 \\
\hline 10 & 24 & 1.21 & 3.33 & 6.27 & 1.63 \\
\hline 11 & 25 & 1.26 & 3.38 & 6.31 & 1.69 \\
\hline 12 & 26 & 1.31 & 3.47 & 6.37 & 1.75 \\
\hline 13 & 27 & 1.36 & 3.40 & 6.34 & 1.81 \\
\hline 14 & 28 & 1.41 & 3.44 & 6.32 & 1.81 \\
\hline 15 & 29 & 1.46 & 3.56 & 6.44 & 1.87 \\
\hline 16 & 30 & 1.51 & 3.74 & 6.56 & 2.00 \\
\hline 17 & 31 & 1.56 & 3.52 & 6.44 & 2.06 \\
\hline 18 & 32 & 1.61 & 3.57 & 6.51 & 2.11 \\
\hline
\end{tabular}

Effect of Internal Friction Angle, $\varphi$ on the Slip Surface

In this part, cohesion and unit weight remained constant at $15 \mathrm{kPa}$ and $15 \mathrm{kN} / \mathrm{m}^{3}$ respectively, while the friction angle varied from $16^{\circ}$ to $32^{\circ}$.

Table-5: Models, Internal Friction Angles Chosen for the Slip Surface Analyses

\begin{tabular}{|l|l|l|l|l|l|}
\hline $\begin{array}{l}\text { Model } \\
\text { No }\end{array}$ & $\begin{array}{l}\text { Friction } \\
\text { Angle }\left(^{\circ}\right)\end{array}$ & $\boldsymbol{\lambda}$ & $\begin{array}{l}\text { Entry Point } \\
\text { Distance, } \mathbf{( m )}\end{array}$ & $\begin{array}{l}\text { Length of } \\
\text { Failure Arc (m) }\end{array}$ & $\begin{array}{l}\text { Factor of } \\
\text { Safety }\end{array}$ \\
\hline 1 & 16 & 0.70 & 2.81 & 5.78 & 1.09 \\
\hline 2 & 17 & 0.66 & 2.76 & 5.76 & 1.11 \\
\hline 3 & 18 & 0.62 & 2.71 & 5.71 & 1.12 \\
\hline 4 & 19 & 0.58 & 2.71 & 5.71 & 1.13 \\
\hline 5 & 20 & 0.55 & 2.66 & 5.66 & 1.14 \\
\hline 6 & 21 & 0.52 & 2.59 & 5.59 & 1.16 \\
\hline 7 & 22 & 0.50 & 2.50 & 5.52 & 1.16 \\
\hline 8 & 23 & 0.47 & 2.57 & 5.57 & 1.19 \\
\hline 9 & 24 & 0.45 & 2.54 & 5.55 & 1.20 \\
\hline 10 & 25 & 0.43 & 2.47 & 5.49 & 1.22 \\
\hline 11 & 26 & 0.41 & 2.40 & 5.42 & 1.22 \\
\hline 12 & 27 & 0.39 & 2.25 & 5.31 & 1.24 \\
\hline 13 & 28 & 0.38 & 2.24 & 5.30 & 1.25 \\
\hline 14 & 29 & 0.36 & 3.44 & 5.36 & 1.27 \\
\hline 15 & 30 & 0.35 & 3.56 & 5.29 & 1.28 \\
\hline 16 & 31 & 0.33 & 3.74 & 5.23 & 1.29 \\
\hline 17 & 32 & 0.32 & 3.52 & 5.27 & 1.31 \\
\hline
\end{tabular}

\section{Effect of Unit Weight, $\varphi$ on the Slip Surface}

In this part, cohesion and friction angle remained constant at $15 \mathrm{kPa}$ and $15^{\circ}$, while the unit weight varied from $16-31 \mathrm{kN} / \mathrm{m}^{3}$. 
Worku Firomsa \& Damtew Tsige, Saudi J Civ Eng, Apr, 2021; 5(3): 60-73

Table-6: Models, Unit Weight Values Selected for the Slip Surface Analyses

\begin{tabular}{|l|l|l|l|l|l|l|l|}
\hline $\begin{array}{l}\text { Model } \\
\text { No }\end{array}$ & $\begin{array}{l}\text { Unit } \\
\text { Weight } \\
(\mathbf{k N} / \mathbf{m 3})\end{array}$ & $\begin{array}{l}\text { Friction } \\
\text { Angle }\left(^{\circ}\right)\end{array}$ & $\begin{array}{l}\text { Cohesion } \\
(\mathbf{k P a})\end{array}$ & $\boldsymbol{\lambda}$ & $\begin{array}{l}\text { Entry Point } \\
\text { Distance, } \mathbf{l} \\
(\mathbf{m})\end{array}$ & $\begin{array}{l}\text { Length of } \\
\text { Failure } \\
\text { Arc (m) }\end{array}$ & $\begin{array}{l}\text { Factor } \\
\text { of } \\
\text { Safety }\end{array}$ \\
\hline 1 & 16 & 15 & 15 & 0.71 & 2.79 & 5.80 & 1.02 \\
\hline 2 & 17 & 15 & 15 & 0.66 & 2.74 & 5.78 & 0.97 \\
\hline 3 & 18 & 15 & 15 & 0.63 & 2.73 & 5.74 & 0.93 \\
\hline 4 & 19 & 15 & 15 & 0.59 & 2.68 & 5.71 & 0.89 \\
\hline 5 & 21 & 15 & 15 & 0.54 & 2.60 & 5.68 & 0.82 \\
\hline 6 & 23 & 15 & 15 & 0.49 & 2.52 & 5.61 & 0.77 \\
\hline 7 & 25 & 15 & 15 & 0.45 & 2.48 & 5.54 & 0.73 \\
\hline 8 & 27 & 15 & 15 & 0.42 & 2.47 & 5.50 & 0.68 \\
\hline 9 & 29 & 15 & 15 & 0.39 & 2.23 & 5.49 & 0.65 \\
\hline 10 & 31 & 15 & 15 & 0.36 & 2.83 & 5.28 & 0.61 \\
\hline
\end{tabular}

Effect of Cohesion (c) and Unit Weight $(\gamma)$ on the Slip Surface

In this part, the friction angle remained constant at $15^{\circ}$ and for cohesion and unit weight, the values were varied from 16 to 31 for both parameters.

Table-7: Models, Unit Weight and Cohesion Values Selected for the Slip Surface Analyses

\begin{tabular}{|l|l|l|l|l|l|l|l|}
\hline $\begin{array}{l}\text { Model } \\
\text { No }\end{array}$ & $\begin{array}{l}\text { Unit } \\
\text { Weight } \\
(\mathbf{k N / m 3 )}\end{array}$ & $\begin{array}{l}\text { Friction } \\
\text { Angle }\left(^{\circ}\right)\end{array}$ & $\begin{array}{l}\text { Cohesion } \\
(\mathbf{k P a})\end{array}$ & $\boldsymbol{\lambda}$ & $\begin{array}{l}\text { Entry } \\
\text { Point } \\
\text { Distance } \\
(\mathbf{m})\end{array}$ & $\begin{array}{l}\text { Length } \\
\text { of } \\
\text { Failure } \\
\text { Arc }(\mathbf{m})\end{array}$ & $\begin{array}{l}\text { Factor } \\
\text { of } \\
\text { Safety }\end{array}$ \\
\hline 1 & 16 & 15 & 16 & 0.75 & 2.88 & 5.86 & 1.08 \\
\hline 2 & 18 & 15 & 18 & 0.75 & 2.88 & 5.86 & 1.08 \\
\hline 3 & 20 & 15 & 20 & 0.75 & 2.88 & 5.86 & 1.08 \\
\hline 4 & 22 & 15 & 22 & 0.75 & 2.88 & 5.86 & 1.08 \\
\hline 5 & 24 & 15 & 24 & 0.75 & 2.88 & 5.86 & 1.08 \\
\hline 6 & 26 & 15 & 26 & 0.75 & 2.88 & 5.86 & 1.08 \\
\hline 7 & 28 & 15 & 28 & 0.75 & 2.88 & 5.86 & 1.08 \\
\hline 8 & 30 & 15 & 30 & 0.75 & 2.88 & 5.86 & 1.08 \\
\hline 9 & 31 & 15 & 31 & 0.75 & 2.88 & 5.86 & 1.08 \\
\hline
\end{tabular}

Effect of Internal Friction Angle ( $\varphi)$ and Unit Weight $(\gamma)$ on the Slip Surface

In this part, cohesion factor remained constant at $15 \mathrm{kPa}$ while the other parameters varied from 15 to 31 .

Table-11: Models, Unit Weight and Internal Friction Angle Values Selected for the Slip Surface Analyses

\begin{tabular}{|c|c|c|c|c|c|c|c|}
\hline $\begin{array}{r}\text { Model } \\
\text { No }\end{array}$ & $\begin{array}{r}\text { Unit } \\
\text { Weight } \\
(\mathrm{kN} / \mathrm{m} 3)\end{array}$ & $\begin{array}{r}\text { Friction } \\
\text { Angle } \\
\left({ }^{\circ}\right)\end{array}$ & $\begin{array}{r}\text { Cohesion } \\
\text { (kPa) }\end{array}$ & $\lambda$ & $\begin{array}{l}\text { Entry Point } \\
\text { Distance (m) }\end{array}$ & $\begin{array}{r}\text { Length of } \\
\text { Failure } \\
\text { Arc (m) }\end{array}$ & $\begin{array}{r}\text { Factor } \\
\text { of Safety }\end{array}$ \\
\hline 1 & 16 & 16 & 15 & 0.66 & 2.84 & 5.81 & 1.04 \\
\hline 2 & 18 & 18 & 15 & 0.52 & 2.61 & 5.61 & 0.97 \\
\hline 3 & 20 & 20 & 15 & 0.41 & 2.51 & 5.54 & 0.92 \\
\hline 4 & 22 & 22 & 15 & 0.34 & 2.32 & 5.36 & 0.88 \\
\hline 5 & 24 & 24 & 15 & 0.28 & 2.08 & 5.17 & 0.85 \\
\hline 6 & 26 & 26 & 15 & 0.24 & 1.94 & 5.07 & 0.83 \\
\hline 7 & 28 & 28 & 15 & 0.20 & 1.66 & 4.85 & 0.81 \\
\hline 8 & 30 & 30 & 15 & 0.17 & 1.65 & 4.84 & 0.80 \\
\hline 9 & 31 & 31 & 15 & 0.16 & 1.57 & 4.79 & 0.79 \\
\hline
\end{tabular}

Effect of Internal Friction Angle, $\varphi$, and Cohesion, c on the Slip Surface $\mathrm{kN} / \mathrm{m}^{3}$.

In this section, cohesion and friction angle varied from 16 to 31 while unit weight remained constant at 15 
Worku Firomsa \& Damtew Tsige, Saudi J Civ Eng, Apr, 2021; 5(3): 60-73

Table-12: Models, Internal Friction Angle and Cohesion Values Selected for the Slip Surface Analyses

\begin{tabular}{|r|r|r|r|r|r|r|r|}
\hline $\begin{array}{r}\text { Model } \\
\text { No }\end{array}$ & $\begin{array}{r}\text { Unit Weight } \\
(\mathbf{k N} / \mathbf{m 3})\end{array}$ & $\begin{array}{r}\text { Friction } \\
\text { Angle }\left(^{\circ}\right)\end{array}$ & $\begin{array}{r}\text { Cohesion } \\
(\mathbf{k P a})\end{array}$ & & $\begin{array}{r}\text { Entry } \\
\text { Distance (m) }\end{array}$ & $\begin{array}{r}\text { Point } \\
\text { Failure } \\
\text { Arc (m) }\end{array}$ & $\begin{array}{r}\text { Factor of } \\
\text { Safety }\end{array}$ \\
\hline 1 & 15 & 16 & 16 & 0.75 & 2.58 & 5.57 & 1.16 \\
\hline 2 & 15 & 18 & 18 & 0.75 & 2.84 & 5.81 & 1.30 \\
\hline 3 & 15 & 20 & 20 & 0.74 & 3.01 & 5.96 & 1.45 \\
\hline 4 & 15 & 22 & 22 & 0.73 & 3.01 & 5.97 & 1.60 \\
\hline 5 & 15 & 24 & 24 & 0.72 & 3.02 & 5.94 & 1.76 \\
\hline 6 & 15 & 26 & 26 & 0.72 & 3.08 & 6.03 & 1.90 \\
\hline 7 & 15 & 28 & 28 & 0.71 & 3.01 & 5.96 & 2.05 \\
\hline 8 & 15 & 30 & 30 & 0.70 & 3.03 & 5.97 & 2.20 \\
\hline 9 & 15 & 31 & 31 & 0.69 & 2.94 & 5.91 & 2.28 \\
\hline
\end{tabular}

\section{Effect of Slope Geometry on the Slip Surface}

It has been shown that slope geometry has a direct correlation with the slope stability as well as soil strength properties [17].
In the last series of models, soil strength parameters remained constant at following values, while the angles $\alpha$ and $\beta$ (shown in Figure-24) in slope geometry varied from $0^{\circ}$ to $18^{\circ}$.Internal friction angle $=$ $15^{\circ}$, Cohesion $=15 \mathrm{kPa}$, Unit weight $=15 \mathrm{kN} / \mathrm{m}^{3}$

Table-13: Effect of Slope Geometry on the Slip Surface

\begin{tabular}{|c|c|c|c|c|c|c|c|}
\hline \multirow{3}{*}{ Model No } & \multirow[t]{3}{*}{$\alpha\left(^{\circ}\right)$} & \multirow[t]{3}{*}{$\beta\left(^{\circ}\right)$} & \multicolumn{4}{|c|}{ Failure Surface } & \multirow[t]{3}{*}{ Factor of Safety } \\
\hline & & & \multicolumn{2}{|c|}{ Center } & \multirow[t]{2}{*}{ Radius } & \multirow{2}{*}{ Length of $\operatorname{arc}(\mathrm{m})$} & \\
\hline & & & $\mathbf{X}(\mathbf{m})$ & $\mathbf{Y}(\mathbf{m})$ & & & \\
\hline 1 & 18 & 0 & 4.81 & 21.27 & 7.51 & 6.16 & 1.11 \\
\hline 2 & 17 & 0 & 3.33 & 23.96 & 10.57 & 6.94 & 1.14 \\
\hline 3 & 16 & 0 & 3.45 & 23.79 & 10.37 & 6.81 & 1.15 \\
\hline 4 & 15 & 0 & 3.14 & 24.13 & 10.82 & 6.75 & 1.15 \\
\hline 5 & 14 & 0 & 3.12 & 23.89 & 10.63 & 6.53 & 1.16 \\
\hline 6 & 13 & 0 & 2.76 & 24.24 & 11.14 & 6.51 & 1.16 \\
\hline 7 & 12 & 0 & 3.29 & 23.55 & 10.25 & 6.27 & 1.16 \\
\hline 8 & 11 & 0 & 2.95 & 23.92 & 10.75 & 6.22 & 1.17 \\
\hline 9 & 10 & 0 & 2.54 & 24.34 & 11.32 & 6.16 & 1.18 \\
\hline 10 & 9 & 0 & 3.08 & 23.58 & 10.40 & 5.96 & 1.17 \\
\hline 11 & 8 & 0 & 5.08 & 20.61 & 6.70 & 5.12 & 1.18 \\
\hline 12 & 7 & 0 & 5.77 & 20.45 & 6.21 & 5.28 & 1.19 \\
\hline 13 & 6 & 0 & 5.12 & 21.75 & 7.75 & 5.72 & 1.19 \\
\hline 14 & 5 & 0 & 2.29 & 24.11 & 11.28 & 5.60 & 1.19 \\
\hline 15 & 4 & 0 & 2.53 & 24.00 & 11.05 & 5.56 & 1.19 \\
\hline 16 & 3 & 0 & 1.99 & 24.54 & 11.81 & 5.50 & 1.20 \\
\hline 17 & 2 & 0 & 1.75 & 24.31 & 11.71 & 5.31 & 1.20 \\
\hline 18 & 1 & 0 & 1.99 & 24.20 & 11.54 & 5.26 & 1.20 \\
\hline 19 & 0 & 0 & 1.37 & 24.81 & 12.40 & 5.21 & 1.20 \\
\hline 20 & 0 & 1 & 2.73 & 23.36 & 10.35 & 5.11 & 1.22 \\
\hline 21 & 0 & 2 & 2.95 & 23.36 & 10.14 & 5.13 & 1.25 \\
\hline 22 & 0 & 3 & 4.01 & 22.53 & 8.84 & 5.21 & 1.27 \\
\hline 23 & 0 & 4 & 4.04 & 22.54 & 8.82 & 5.28 & 1.28 \\
\hline 24 & 0 & 5 & 4.54 & 21.75 & 7.86 & 5.24 & 1.28 \\
\hline 25 & 0 & 6 & 4.16 & 22.11 & 8.34 & 5.30 & 1.29 \\
\hline 26 & 0 & 7 & 4.28 & 22.11 & 8.23 & 5.34 & 1.32 \\
\hline 27 & 0 & 8 & 5.44 & 19.94 & 5.71 & 4.89 & 1.33 \\
\hline 28 & 0 & 9 & 5.67 & 20.75 & 6.27 & 5.32 & 1.36 \\
\hline 29 & 0 & 10 & 5.43 & 20.98 & 6.57 & 5.37 & 1.37 \\
\hline 30 & 0 & 11 & 5.45 & 20.99 & 6.55 & 5.45 & 1.39 \\
\hline 31 & 0 & 12 & 5.19 & 21.24 & 6.88 & 5.51 & 1.40 \\
\hline 32 & 0 & 13 & 5.24 & 20.95 & 6.55 & 5.41 & 1.42 \\
\hline 33 & 0 & 14 & 6.15 & 20.22 & 5.47 & 5.50 & 1.45 \\
\hline 34 & 0 & 15 & 6.28 & 20.10 & 5.32 & 5.70 & 1.46 \\
\hline 35 & 0 & 16 & 6.28 & 20.10 & 5.33 & 5.70 & 1.47 \\
\hline 36 & 0 & 17 & 5.79 & 20.59 & 5.92 & 5.71 & 1.48 \\
\hline 37 & 0 & 18 & 5.78 & 20.37 & 5.67 & 5.59 & 1.50 \\
\hline
\end{tabular}


Worku Firomsa \& Damtew Tsige, Saudi J Civ Eng, Apr, 2021; 5(3): 60-73

Effect of Soil Strength and Geometry Parameters on Factor of Safety

In order to weigh the effect of soil strength parameters and geometry parameters on the factor of safety, the factor of safety versus these soil strength parameters were drawn and offered in the subsequent figures.

\section{Effect of Cohesion, $c$ on the Factor of Safety, FS}

In this part, the influence of cohesion on the factor of safety has been shown. As it was expected, increasing the cohesion value which is a resistant force increased the value of factor of safety. Effect of Internal Friction Angle on the Factor of Safety

In this part, the influence of friction angle on the factor of safety has been shown. As it was expected, increasing the friction angle which is the other resistant force increased the value of factor of safety.

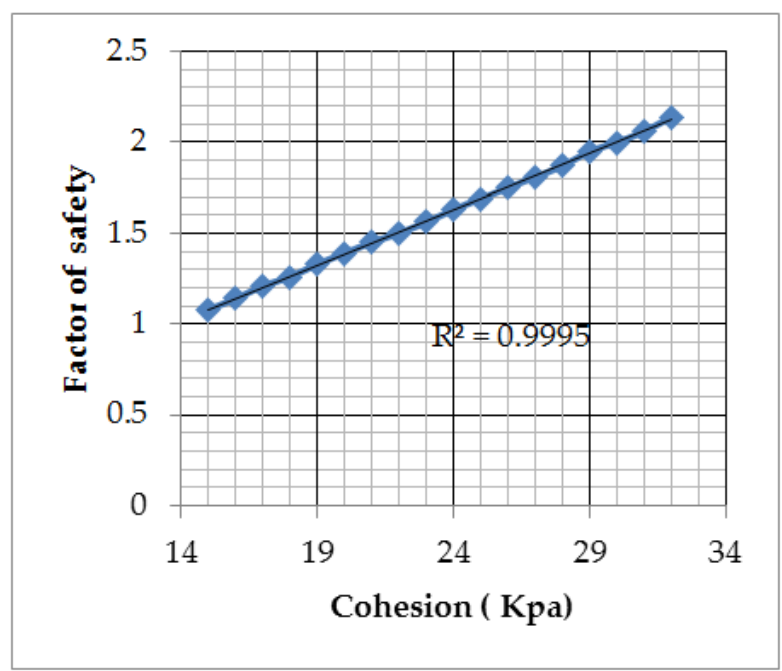

Fig-3: Effect of Cohesion (c) on the Factor of Safety, FS

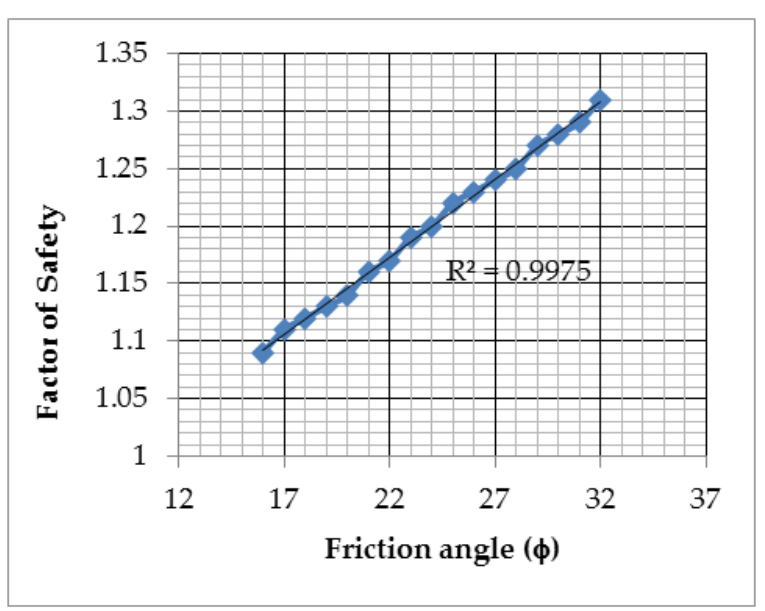

Fig-4: Friction angle $(\phi)$ on the Factor of Safety, FS

Figure-3 above shows that there is linear relation between cohesion and factor of safety. As it can be seen from Figure 4, the relationship between the friction angle $(\phi)$ and the factor of safety, FS is almost linear with a squared $\mathrm{R}$ factor of 0.99

Effect of Unit Weight on the Factor of Safety

The effect of unit weight of the soil on the factor of safety was shown in Figure 5. As it can be seen from the figure, the unit weight as the main driving force applied in the soil mass is inversely proportional to the factor of safety.

\section{The Combined Effect of Cohesion and the Unit} Weight on the Factor of Safety

The effect of cohesion together with the unit weight of the soil on the factor of safety was studied in this section. Here, cohesion and the unit weight of the soil were increased together, while their ratio remained constant. The results specify that the potential slip surface is touched by the combination of $\mathrm{c}$ and $\varphi$ whose function is defined as $\lambda$ which is equal to: $\lambda=\frac{c}{(\gamma h \tan \phi)}$

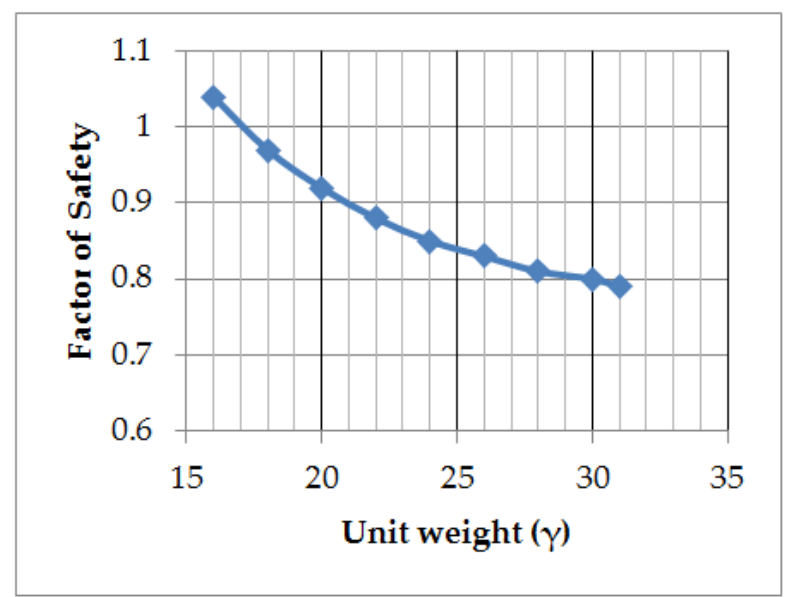

Fig-5: The Unit Weight on the Factor of Safety

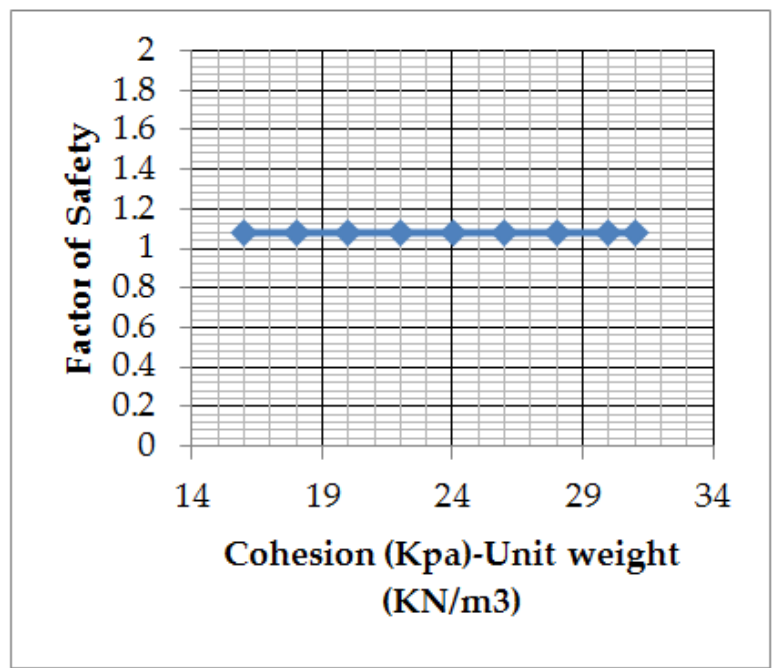

Fig-6: The Combined Effect of c- $\gamma$ on the Factor of Safety

As it can be seen from the Figure-5, the unit weight as the main driving force applied in the soil mass is inversely proportional to the factor of safety. 
Worku Firomsa \& Damtew Tsige, Saudi J Civ Eng, Apr, 2021; 5(3): 60-73

And also Figure 6 indicates that factor of safety remains constant while $\lambda$ value remains the same.

The Combined Effect of Internal Friction and the Unit Weight on the Factor of Safety

In this part, the value of internal friction angle by unit weight is increasing by increasing both of them. The factor of safety versus $\tan (\phi) * \gamma$ curve was drawn and shown in Figure-7.

The Combined Effect of Internal Friction and Cohesion on the Factor of Safety

In this part, since the potential failure surface is anticipated to be affected by the combination of $\mathrm{c}$ and $\varphi$ values, the relation between the factors of safety andcandtan $(\varphi)$ is shown in Figure 8. Since both of these shear strength parameters are resisting forces, increasing these two values leads to an increase in the value of factor of safety.

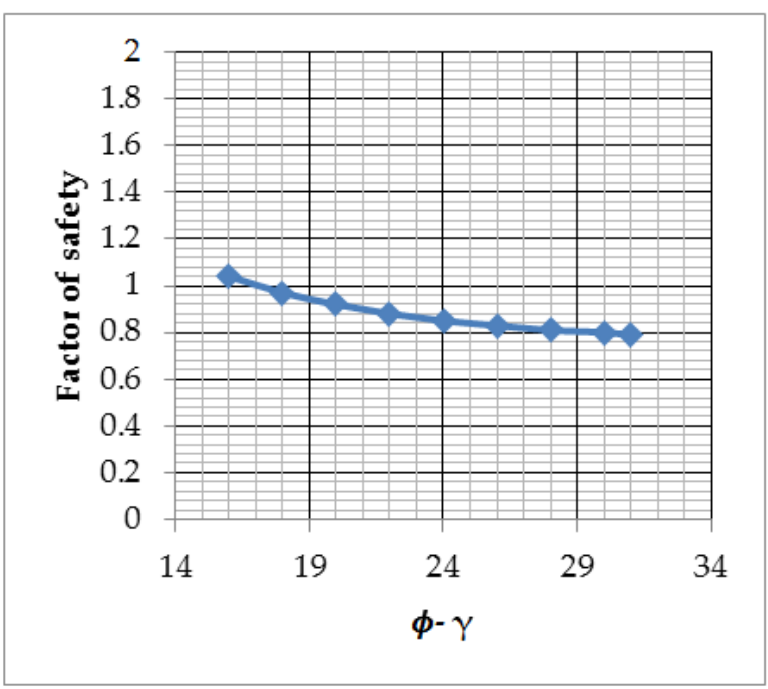

Fig-7: The Combined Effect of $\phi$ - $\gamma$ on the Factor of Safety

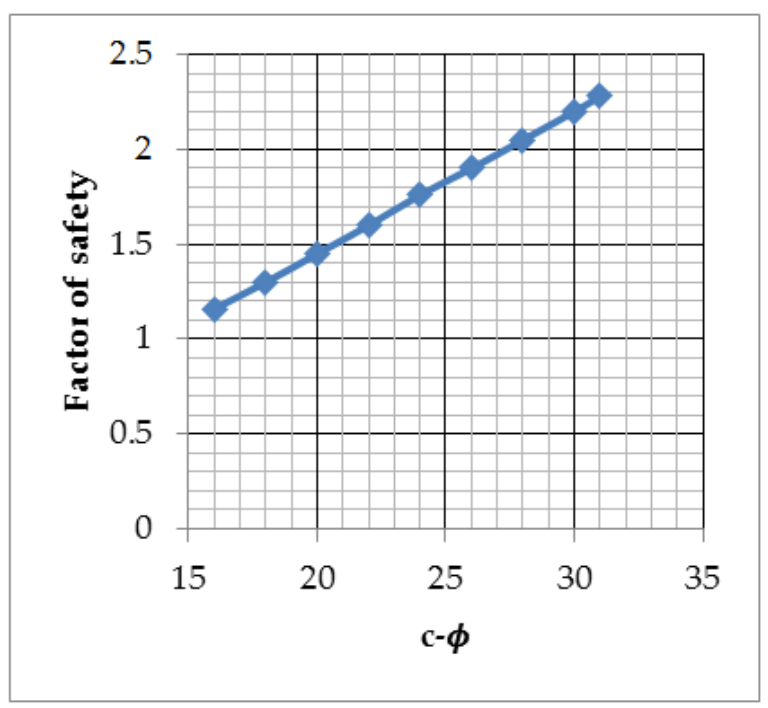

Fig-8: The Combined Effect of Friction Angle and Cohesion on the Factor of Safety
As it can be seen in Figure-7, reduction in the factor of safety value was obtained by increasing the value of $\tan (\varphi) * \gamma$. This is because of the movement of failure surface to the top and hence decreasing the length of failure arc and so a decrease in effect of resisting forces.

\section{Effect of Slope Geometry on the Factor of Safety}

To study the effect of geometry on the factor of safety, two slope angles $\alpha$, and $\beta$ (introduced in the methodology section) have been varied and their effect on factor of safety has been observed.

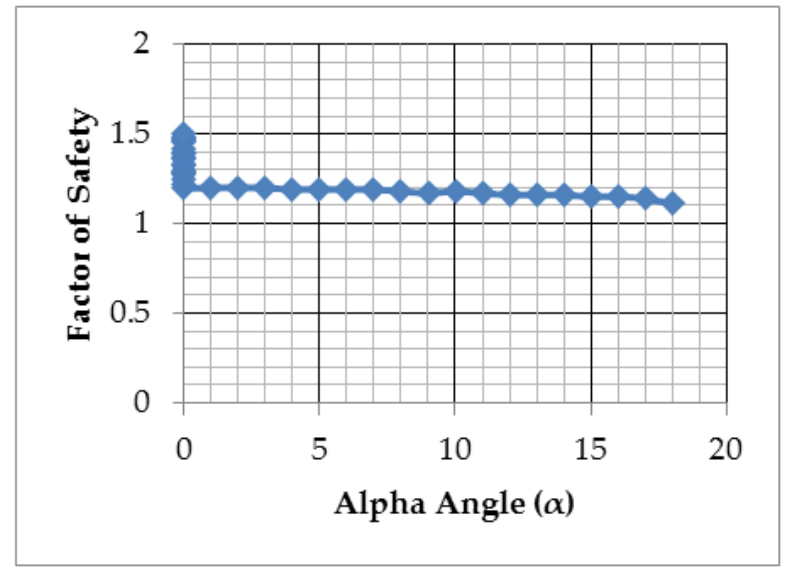

Fig-9: Effect of Alpha Angle on Safety Factor

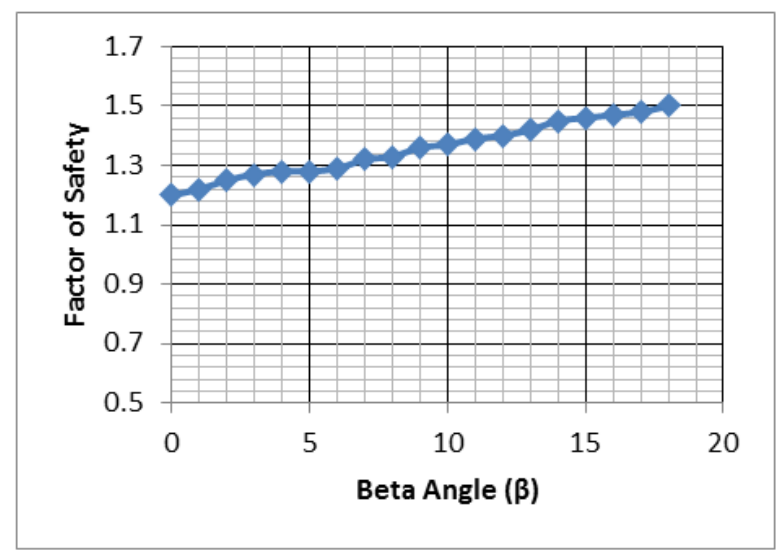

Fig-10: Effect of Beta Angle ( $\beta$ ) on Factor of Safety

Figure-9 shows that by changing the alpha angle, no noteworthy variation is observed in the factor of safety until $16^{\circ}$, and afterwards FS starts to decrease. This is because of the fact that increasing alpha angle can be acted as if adding an extra overhead surcharge on the slope surface. Until the angle of $16^{\circ}$, increasing the failure surface and consequently increasing the length of arc, generate more resisting force and make the factor of safety constant. Although this increase in the failure surface generates more resisting force, it generates an increase in deriving force (weight of failure surface) simultaneously. Therefore, the factor of safety stays constant. For angles greater than $16^{\circ}$, the increase in deriving force approaches to the resisting force value and from this value of angle onwards, the 
driving force gets bigger than resisting force, and thus, a drop can be seen in the factor of safety value.

Figure-10 shows that by increasing the Beta angle, the factor of safety increases significantly. The reason for this behaviour is that by increasing the beta angle, only the length of failure arc increases (as resisting force) and the mass of failure shape(as deriving force) remains almost constant. So, increase in the length of the arc increases the resisting force and hence the factor of safety increases.

\section{Effect of Soil Strength and Geometry Parameters on Slip Surface}

En route for study the effect of each soil parameter on slip surface, length of failure arc, as a quantitative variable has been chosen to be studied. The following figures will be presented in order to show this effect.

Effect of Cohesion, c on the Length of Failure Arc, L

It can be seen in the figure that with increasing the value of cohesion, length of failure surface will increase. The reason is that, in the case of the location of the failure surface remaining constant, as the c factor increases, the resisting force gets bigger as well as factor of safety. So to find the minimum FS (which is the main goal of the slope stability analysis), the driving force should increase, which can be achieved by increasing the slope failure area. This leads to a greater length of failure arc (L) and thus smaller factor of safety value.

\section{Effect of Internal Friction Angle, $\varphi$ on the Length of Failure Arc, L}

Referring to the same explanation in the previous section, it can be expected that length of arc, $\mathrm{L}$ should be in a direct relation with phi, but as it can be seen in Figure-12, L and phi are inversely related.

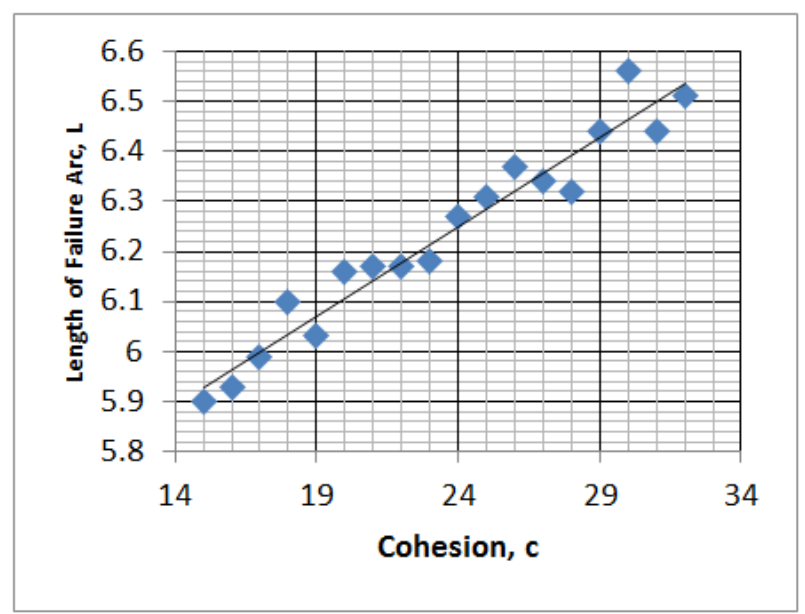

Fig-11: Effect of Cohesion, $c$ on the Length of Failure Arc, L

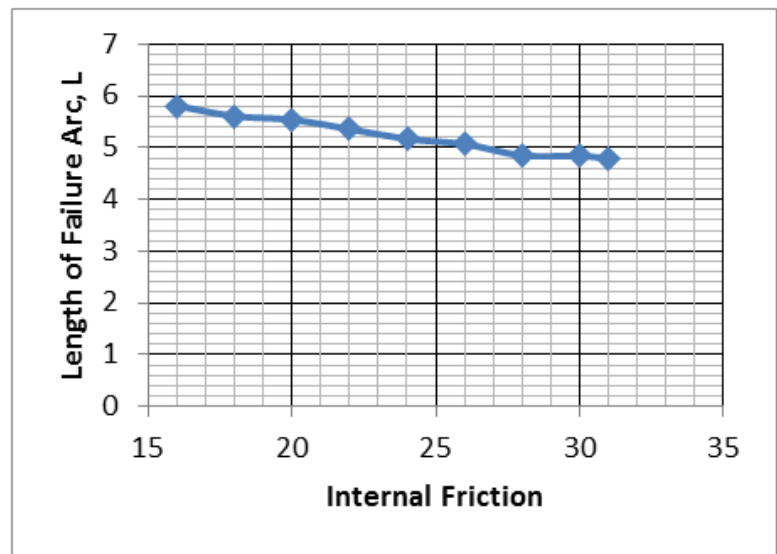

Fig-12: Effect of Internal Friction, $\gamma$ on the Length of Failure Arc, $\mathbf{L}$

This inverse relation in Figure-12 is in line with [18] study which states that "when the slope geometry, unit weight and pore water pressure distribution in homogeneous soil slope are given, the location of the critical slip surface for particular method of slices is related only to $\mathrm{c} \tan (\varphi)$ ratio of that slope", this study shows that the position of the slip surface and thus the length of failure arc is in an inverse relation with internal friction angle.

Effect of Unit Weight, $\gamma$ on the Length of Failure Arc, $L$

In this section, effect of unit weight on the length of arc is studied and shown in Figure-13. By considering $\lambda$, the failure slip surface moves toward the face of the slope, meanwhile by decreasing $L$, the effects of cohesion and friction angle as resistance forces decrease and hence smaller factor of safety will be achieved.

\section{The Combined Effect of Cohesion and Unit Weight on the Length of Failure Arc, $L$}

In this part, cohesion and unit weight decrease together in a way that their ratio remains constant. The result can be seen in Figure-14.

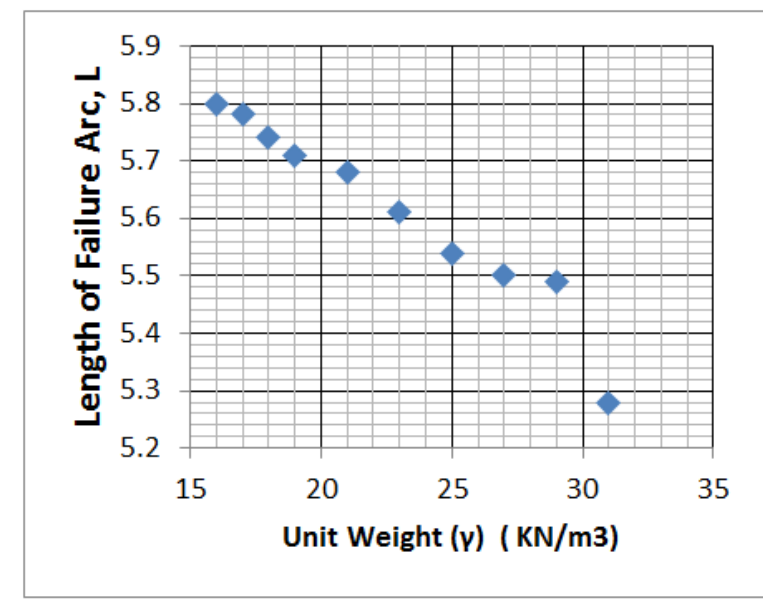

Fig-13: Effect of Unit Weight $(\gamma)$ on the Length of Failure Arc, $\mathbf{L}$ 
Worku Firomsa \& Damtew Tsige, Saudi J Civ Eng, Apr, 2021; 5(3): 60-73

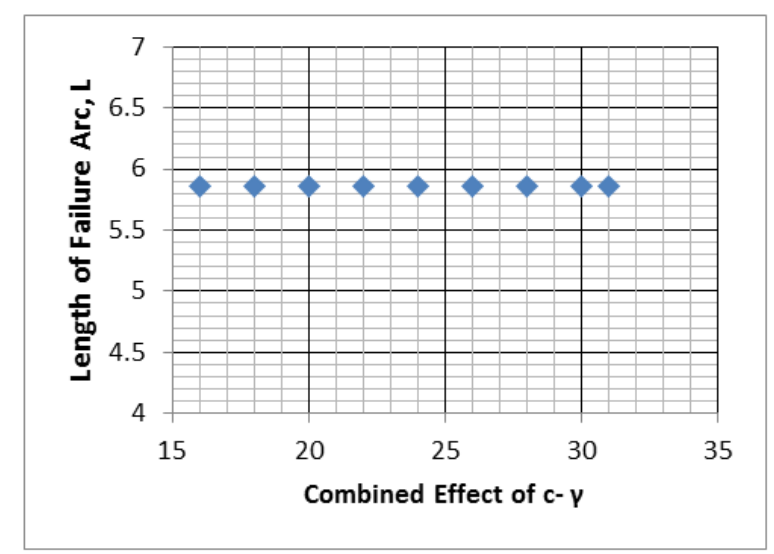

Fig-14: The Combined Effect of $c-\gamma$ on the Length of Failure Arc, $\mathbf{L}$

As it can be seen in Figure-13 by increasing the unit weight, weight of the falling shape increases, and this leads to a smaller factor of safety. And also as in Figure-14, Constant ratio of unit weight over c, leads to a constant $\lambda$. As it has been mentioned in study of [16], this means same failure shape and hence a constant value for $\mathrm{L}$.

The Combined Effect of Friction Angle and Unit Weight on the Length of Failure Arc, L

In order to show the influence of variation of unit weight and internal friction angle on length of failure arc, the Figure-15 has been drawn.

The Combined Effect of Friction Angle and Cohesion on the Length of Failure Arc, $L$

To illustrate the combined effect of varying cohesion and internal friction angle on the length of failure arc, the following Figure-16 has been drawn.

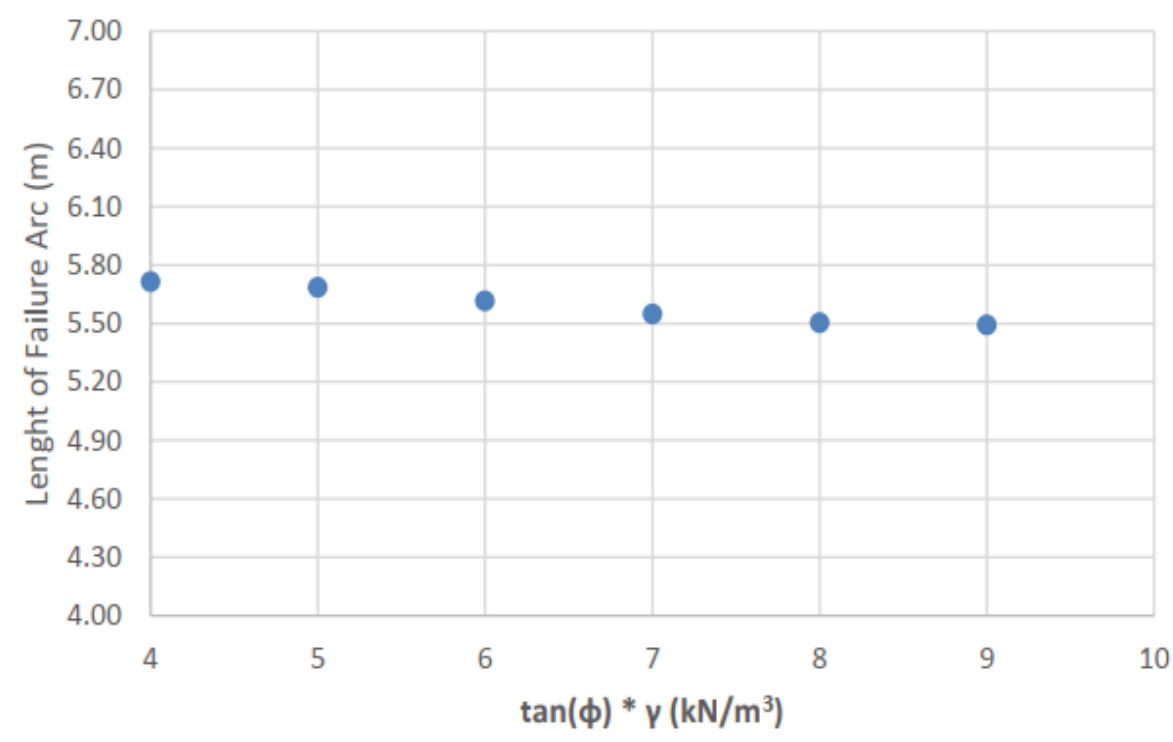

Fig-15: The Combined Effect of $\phi$ - $\gamma$ on the Length of Failure Arc, L

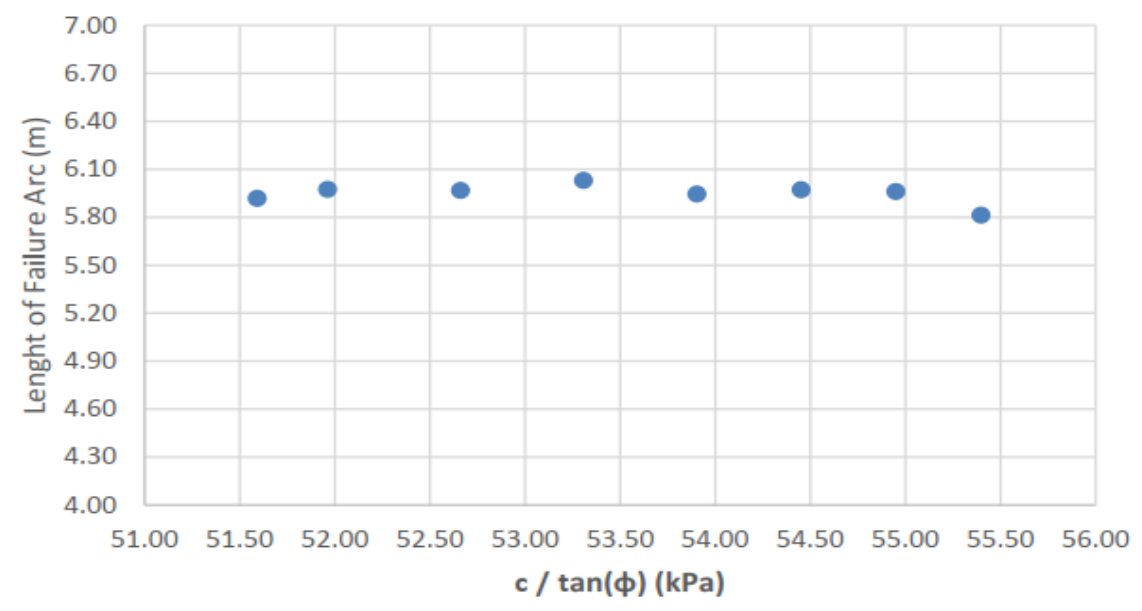

Fig-16: The Combined Effect of $\phi$ - C on the Length of Failure Arc, L 
It can be seen from Figure-15 that increasing the value of $\gamma * \tan \varphi$ will leads to a decrease in the length of failure surface. This is in harmony when considering the value of $\lambda$, by increasing this value, $\lambda$ decreases; smaller $\lambda$ means a failure surface closer to the slope surface and hence smaller length of failure arc.

From Figure-16, it can be seen that at relatively constant value of $c / \tan \varphi(51.50 \sim 55.50 \mathrm{kPa})$, $\mathrm{L}$ will remain relatively constant. Since constant $c / \tan \varphi$ leads to a constant $\lambda$, and constant $\lambda$ means a constant failure surface, the length of arc remains constant as well.

Effect of Slope Geometry on the Length of Failure Arc, $\mathrm{L}$

To observe the effect of slope geometry on the failure surface, length of failure arc asa quantitative value has been measured and drawn in the following figures (Figure 17 and 18).

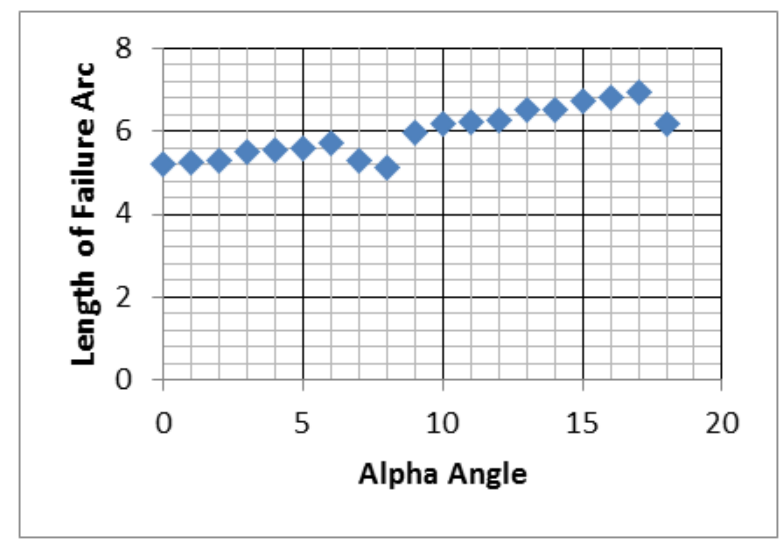

Fig-17: Effect of Alpha Angle on Length of Failure Arc

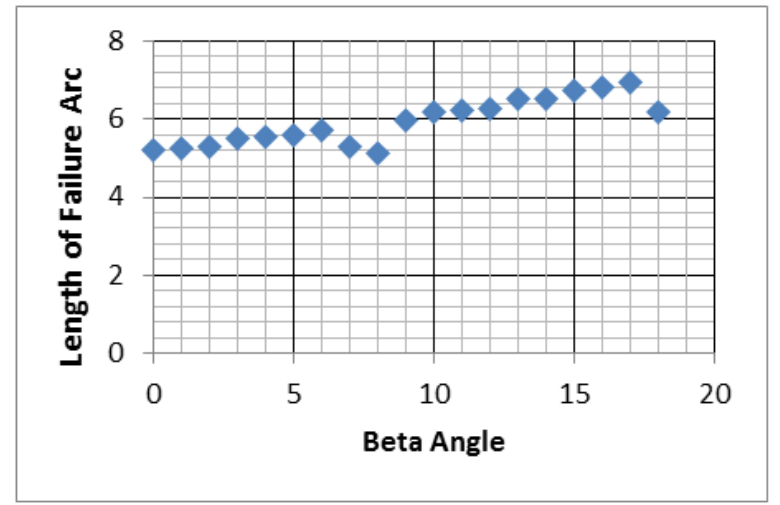

Fig-18: Effect of Beta Angle on Length of Failure Arc

Figure-17 show that, by increasing the Alpha angle, the position of the failure surface does not vary significantly. On the other hand, increase in the beta angle will lead to a slightly larger length of failure arc (Figure-18)

\section{Locating Failure Surface}

Geometry dictates that for locating the failure surface, at least two parameters related to failure surface need to be known. For this reason, length of failure arc, and slip surface entry point will be used. In the following sections correlation between soil strength parameters and length of failure arc as well as slip surface entry distance were studied to find a formula to make them known by knowing soil strength parameters.

In order to relate the slip surface to the soil strength parameters and slope geometry, a dimensionless variable called $\lambda$ has been hired. Up to this point, relation of Lambda to the slip surface has been explained as a qualitative value for how deep or shallow is the failure surface according to [16].

\section{Length of Failure Arc, L}

To find the relation between Lambda and length of failure arc, Figure 19 will be drawn based on the outcomes obtained from the GEO5 software.

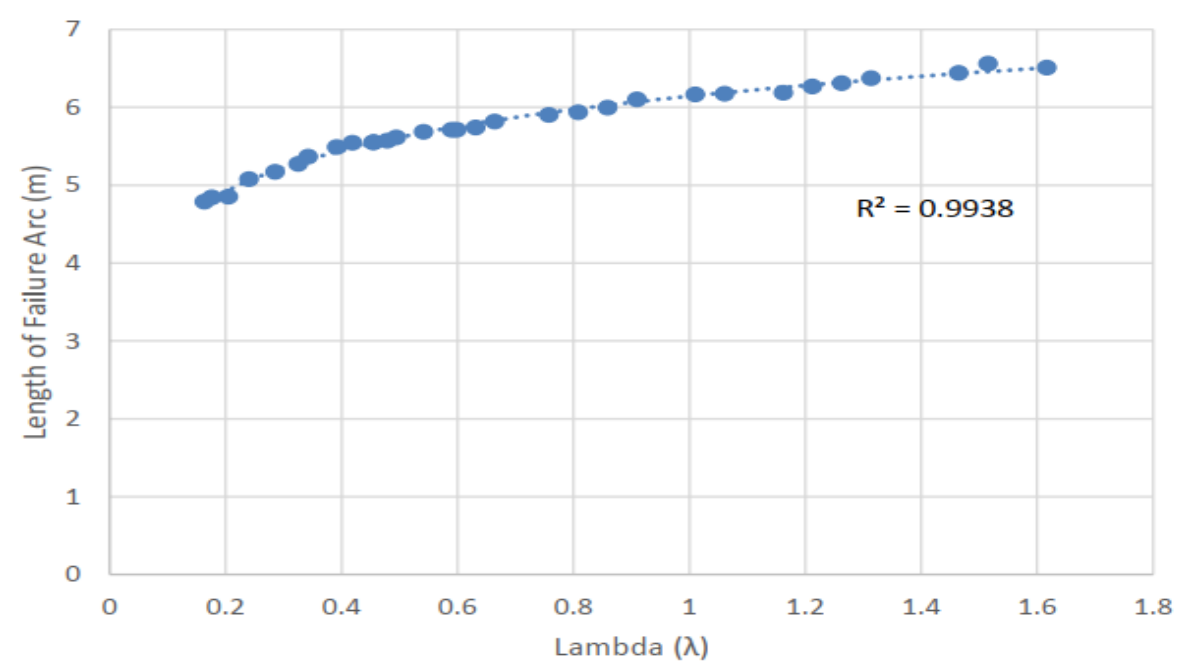

Fig-19: Length of Failure Arc vs. Lambda $(\lambda)$ by GEO5 
As it can be seen from figure 19, there is logarithmic trend line for the length if failure arc versus lambda. In GEO5, an optimization technique is used, hence, slopes are more close to the real failure surfaces, although since finding the real failure surfaces too much time consuming, application will stop the optimization at a desired accuracy level. This usage of the optimization technique, will give a more in trend data in L- $\lambda$ (Figure-19).

Considering the above Figure-19, it can be accepted that there is a clear logarithmic relation between length of failure arc and the lambda parameter, and keeping in mind that lambda itself is a dimensionless parameter related to soil slope properties, it is safe to say that length of failure arc is predictable based on the slope properties using the following equation derived from a non-linear regression using SPSS software.

$$
\mathrm{L}=0.76 \ln \left(\frac{c}{(\gamma h \tan (\phi))}\right)+6.14
$$

Slip Surface Entry Point Distance, le

Another parameter to locate the failure surface is the entry point of the slip surface. For this purpose, the distance from the edge of the slope was introduced as " $1 \mathrm{e}$ " as shown in Figure 21.

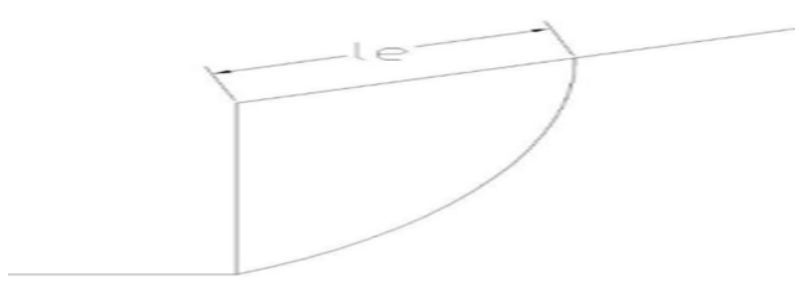

Fig-20: Slip Surface Entry Point Distance, le

To find the relation between Lambda and Slip Surface Entry Point Distance, Figure 22 was drawn based on the outcomes obtained from the GEO5 software.

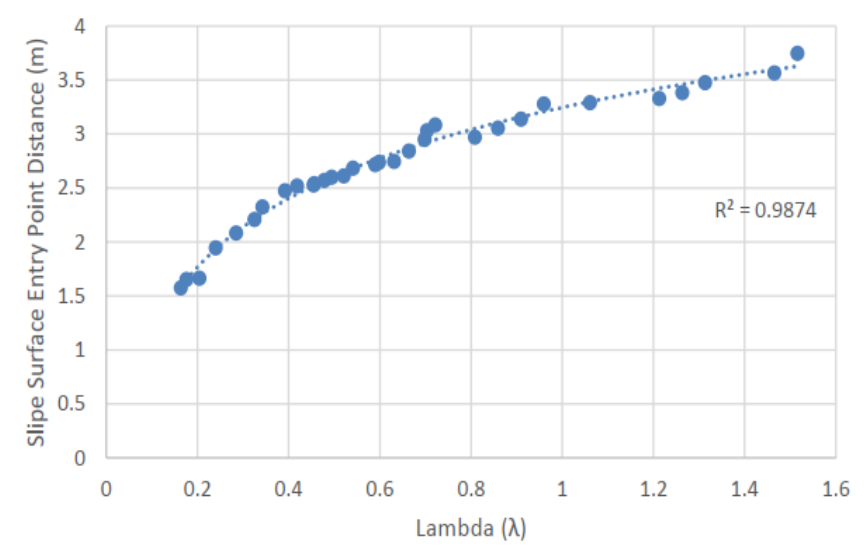

Fig-21: Lambda versus Slip Surface Entry Point Distance

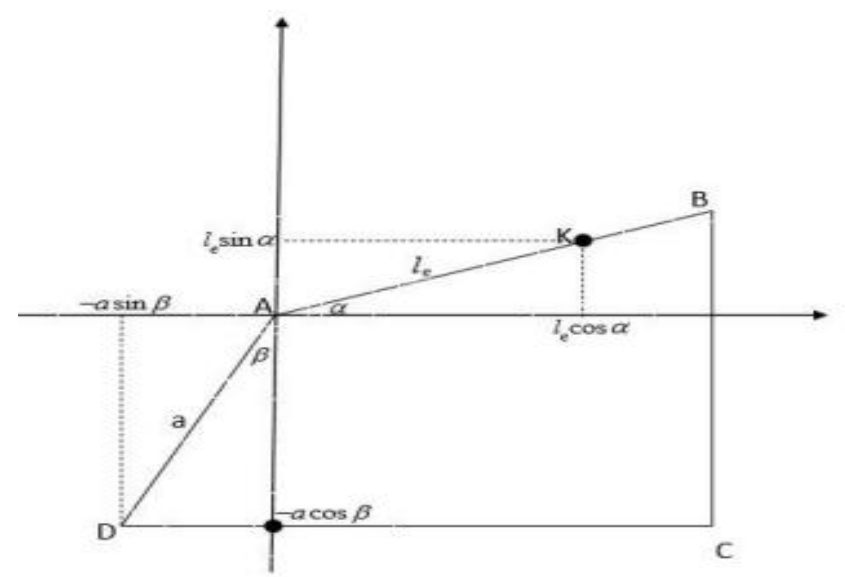

Fig-22: Locating Slip Surface 
As it can be seen in the Figure-22, there is a logarithmic relation between lambda and le. This figure has been drawn using 72 models, analysed by GEO5 software.

Considering Figure-23, it can be accepted that there is a clear logarithmic relation between slip surface entry point distance, le, and the lambda parameter.

Keeping in mind that lambda itself is a dimensionless parameter related to soil slope properties, it is safe to say that slip surface entry point is predictable based on the slope properties using the following equation derived from a non-linear regression using SPSS software.

$$
l_{e}=0.91 \ln \left(\frac{c}{(\gamma h \tan (\phi))}\right)+3.24 \ldots
$$

\section{Locating Slip Surface}

To locate the slip surface, the following geometrical study has been carried out. In Figure 51, K is the slip surface entry point and D is the exit point. Regarding the previous studies, D almost always is located on the lowest point of slope. Hence, "a" can be assumed to be equal to $h / \cos \beta$, in which " $h$ " is the height of slope.

To solve this problem, we assume the following equation for the failure circle formula.

$$
\left(x-x_{0}\right)^{2}+\left(y-y_{0}\right)^{2}=r^{2} .
$$

In Equation $33 x 0, y 0$ and $\mathrm{r}$, are unknown variables so in order to find them, three equations are needed. Since entry and exit points shall satisfy the Equation (4), two of the equations will be created by inserting their coordinates in the Equation (4).

To create the third equation, length of the failure arc will be used as a known parameters (using Equation 31) and it will be inserted into the following formula of curve length integral.

Length of curve is equal to: $p=\int_{x_{d}}^{x_{k}} \sqrt{\left(1+\left(y^{\prime}\right)^{2}\right.} d x$ in which $\mathrm{p}$ is the length of failure arc, L, and: $y$, $=\frac{x-x_{0}}{\sqrt{r^{2}-\left(x-x_{0}\right)^{2}}}$, Hence: $\mathrm{L}=\int_{x_{d}}^{x_{k}} \frac{r}{\sqrt{r^{2}-\left(x-x_{0}\right)^{2}}} d x$

Hence, the three equations needed to calculate the coordinates of failure circle will be as follow:

$$
\left\{\begin{array}{c}
\left(l_{e} \cos \alpha-x_{0}\right)^{2}+\left(l_{e} \sin \alpha-y_{0}\right)^{2}=r^{2} \\
\left(-a \cos \beta-x_{0}\right)^{2}+\left(-a \sin \beta-y_{0}\right)^{2}=r^{2} \\
r\left(\sin ^{-1} \frac{l_{e} \cos \alpha-x_{0}}{r}-\sin ^{-1} \frac{-a \sin \beta-y_{0}}{r}\right)=L
\end{array}\right.
$$

By inserting known parameters (a, le, $\alpha, \beta$, and L) the above equation system is solvable by numerical methods. The answer of this system will be $x 0, y 0$, and $r$ which are the coordinates of failure circle centre and its radius.

\section{CONCLUSIONS}

Friction angle $(\varphi)$ and cohesion (c), as resistance forces, are directly related to factor of safety while unit weight $(\gamma)$, as driving force, is inversely related to factor of safety. Increasing the value of cohesion (c) leads to an increase in the value of the length of failure arc (L) and increasing the value of friction angle $(\varphi)$ leads to a reduction in the value of the length of failure arc (L). The greater unit weight of soil $(\gamma)$ gets, the greater is the value of the length of failure arc (L). Increasing the Alpha angle until a specific angle does not have any significant effect on the factor of safety. On the other hand, increasing the Beta angle directly affects the Factor of safety.
Increasing the Alpha angle, leads to an increase in the length of failure arc. However, changing the Beta angle does not significantly affect the length of failure arc Constant value of lambda $(\lambda)$ results in constant factor of safety and constant slip surface. Greater value of lambda $(\lambda)$ means a deeper slip surface and a greater value for length of failure arc $(\mathrm{L})$. There is no relation between factor of safety and length of failure $\operatorname{arc}(\mathrm{L})$. The length of failure $\operatorname{arc}(\mathrm{L})$ is logarithmically related to lambda $(\lambda)$ using following formula:

$$
\mathrm{L}=0.76 \ln \left(\frac{c}{(\gamma h \tan (\phi))}\right)+6.14
$$

The slip surface entry point distance from the slope edge (le) is also logarithmically related to lambda $(\lambda)$. This correlation can be formulated as:

$$
l_{e}=0.91 \ln \left(\frac{c}{(\gamma h \tan (\phi))}\right)+3.24
$$

The failure surface can be found by solving the following equation system:

$$
\left\{\begin{array}{c}
\left(l_{e} \cos \alpha-x_{0}\right)^{2}+\left(l_{e} \sin \alpha-y_{0}\right)^{2}=r^{2} \\
\left(-a \cos \beta-x_{0}\right)^{2}+\left(-a \sin \beta-y_{0}\right)^{2}=r^{2} \\
r\left(\sin ^{-1} \frac{l_{e} \cos \alpha-x_{0}}{r}-\sin ^{-1} \frac{-a \sin \beta-y_{0}}{r}\right)=L
\end{array}\right.
$$


Where $x_{0}, y_{0}$ are the coordinates of the failure circle center and $\mathrm{r}$ is the radius of the circle.

\section{REFERENCES}

1. Lourens, J. P., Czapla, H., \& Parrock, A. L. (1989). Finite element analysis of failure and structural rehabilitation of a high embankment on a soft foundation. The Civil Engineer in South Africa, 211-220.

2. Lechman, J. B., \& Griffiths, D. V. (1999). Analysis of progressive failure of earth slopes by finite elements. In: Wardle, G. R. (Eds.), Geotechnics for Developing Africa, Proceedings of the 12th African Regional Conference of the ISSMGE., Balkema, Rotterdam, pp. 577-596.

3. Chowdhury, R. N. (1978). Slope analysis. Developments in Geotechnical Engineering, 22, 11-15

4. Boutrup, E., \& Lovell, C. W. (1980). Searching techniques in slope stability analysis, Engineering Geology, 16, 51-61.

5. Siegel, R. A., Kovacs, W. D., \& Lovell, C. W. (1981). Random search generation in stability analysis. ASCE, 107(GT7), 996-1002.

6. Bishop, A. W., \& Bjerrum, L. (1960). The relevance of the triaxial test to the solution of stability problems, In Proc. ASCE Research Conference on Shear strength of Cohesive Soils, Boulder, Colorado, pp. 437-501.

7. Bromhead, E. N. (1992). The Stability of Slopes, 2nd ed. Blackie Academic and Professional, London.

8. Carter, R. K. (1971). Computer oriented slope stability analysis by method of slices, Master's thesis, Purdue University.

9. Siegel, R. A. (1975). Computer analysis of general slope stability problems, Joint Highway Research Reports, 75-8 and 75-9, Purdue University.
10. Revilla, J., \& Castillo, E. (1977). The calculus of variation applied to stability problems. Ge'otechnique, 27, 1-11.

11. Nguyen, V. U. (1985), Determination of critical slope failure surfaces. Journal of Geotechnical Engineering, 111(2), 238-250.

12. Celestino, T. B., \& Duncan, J. M. (1981). Simplified search for non-circular slip surface, Proceedings of the 10th International Conference on Soil Mechanics and Foundation Engineering.

13. Li, K. S., \& White, W. (1987). Rapid evaluation of the critical slip surface in slope stability problems. International Journal of Numerical and Analytical Methods in Geomechanics, 11, 449473.

14. Baker, R. (1980). Determination of critical slip surface in slope stability computations. International Journal of Numerical and Analytical Methods in Geomechanics, 4, 333359.

15. Goh, A. T. C. (1999). Genetic algorithm search for critical slip surface in multiple-wedge stability analysis. Canadian Geotechnical Journal, 36, 382-391.

16. Li, Y., Lin, H., Li, Y., \& Cao, J. (2011). Association between socio-psycho-behavioral factors and male semen quality: systematic review and meta-analyses. Fertility and sterility, 95(1), 116-123.

17. Namdar, M., Steffel, J., Vidovic, M., Brunckhorst, C. B., Holzmeister, J., Lüscher, T. F., ... \& Duru, F. (2011). Electrocardiographic changes in early recognition of Fabry disease. Heart, 97(6), 485-490.

18. Jiang, J. C., \& Yamagami, T. (2006). Charts for estimating strength parameters from slips in homogeneous slopes. Computers and Geotechnics, 33(6-7), 294-304. 